\title{
METODOLOGÍA DE REPRODUCCIÓN DE GRABADOS RUPESTRES EN GALICIA: LEVANTAMIENTO DE CALCOS SOBRE PLÁSTICO ${ }^{1}$
}

\author{
YOLANDA SEOANE VEIGA ${ }^{2}$
}

\begin{abstract}
Resumen
En el último siglo los estudios sobre reproducción de arte rupestre gallego han evolucionado de una manera muy poco dinámica, provocando la falta de una metodología y codificación generales para los calcos. En este artículo proponemos el método que consideramos más adecuado para el caso gallego y un protocolo para su uso tanto en campo como en gabinete, al mismo tiempo que se hace una descripción de las fases de trabajo.
\end{abstract}

\section{Palabras Clave}

Arte rupestre gallego, observación, reproducción, métodos en $2 \mathrm{D}$ y $3 \mathrm{D}$, calco sobre plástico.

\begin{abstract}
The studies about recording of Galician rock art have developed little in the last century, which has brought the absence of a general methodology and codification for every reproductions. In this paper, we propose the method what we consider the most appropriate for Galicia case, and suggest a protocol for the use in the field and the laboratory. Also, we make a description about the phases of the work.
\end{abstract}

\section{Key Words}

Galician Rock Art, observation, recording, 2D and $3 \mathrm{~d}$ methods, tracing.

${ }^{1}$ Fecha de entrega: 14 de abril del 2004.

2 Becaria predoctoral del Laboratorio de Arqueoloxía. Instituto de Estudios Galegos Padre Sarmiento (CSIC-XuGa). 


\section{PRESENTACIÓN}

Desde finales del siglo XIX, y, sobre todo, en el siglo XX, las investigaciones en arte rupestre gallego han experimentado un sistemático desarrollo generando un acuerdo universal de garantizar la transmisión de esta parte del patrimonio arqueológico a las futuras generaciones. Sin embargo, esta evolución no ha sido equitativa en todos los campos de estudio, a pesar del respeto que se le ha tenido a la interpretación y significado, y del esfuerzo realizado por los investigadores que han afrontado la problemática rupestre en estos últimos cien años, muy poco se ha hablado sobre el registro de estos grabados. Sin duda, la investigación en arte rupestre, se ha visto eclipsada por la falta de rigor tanto en documentación como en reproducción, permaneciendo estas últimas estancadas en lo que respecta al desarrollo de una metodología propia. El desinterés, no sólo, por aplicar, sino también, por estudiar criterios rigurosos en este ámbito ha sido un patrón constante en la investigación del siglo pasado, y ha generado un vacío de criterio documental del que se resienten aún hoy en día los estudios de arte rupestre en nuestra comunidad. Esta exclusión ha provocado la inexistencia de unas normas para codificar la información y que cada investigador trate de adaptar individualmente su obra al original rupestre, recurriendo a toda una serie de recursos que nunca han sido estandarizados. Además, ha generado una ralentización en la utilización de los avances que la tecnología ofrece actualmente, colocándonos muy por detrás de lo que ocurre en otras zonas con manifestaciones rupestres.

Ahora más que nunca, se percibe la necesidad, por un lado, de establecer unas convenciones mínimas para el tratamiento de la información tanto previa como resultante del proceso de reproducción que nos permita contar con una metodología y un protocolo básicos, y, por otro, de introducir sistemas de reproducción más rigurosos con el gradual mejoramiento de las técnicas fotográficas, la incorporación y adaptación de métodos de documentación internacionales y la aplicación de procesos digitales de manipulación de imagen. La importancia de un buen registro $^{3}$ para generar conocimiento en arte rupestre es obvio, se encuentra en la base de cualquier investigación. A pesar de que el arte rupestre es una manifestación que ha perdurado en el tiempo y ha llegado a nuestros tiempos conservando al menos buena parte de sus características originales, desgraciadamente casi nunca pode-

\footnotetext{
${ }^{3}$ Entendiendo en este caso como registro la suma de la recogida de información tanto gráfica como escrita de las característica un petroglifo (documentación), así como del proceso por el cual se efectúa una copia del original (reproducción).
}

Cuadernos de Estudios Gallegos, Tomo LII, Fascículo 118, Santiago 2005. (Págs. 81 - 115) 
mos trabajar directamente sobre él. Esto significa que necesitamos sistematizar la información que éste contiene, es decir, seleccionarla, codificarla y hacerla accesible. Será sobre este registro representado sobre el que trabajemos para plantear las hipótesis a través de las cuales se va a generar el conocimiento válido que nos permitirá acceder a la gestión y difusión del arte rupestre. De todo esto se deducen dos conclusiones, que la investigación sobre documentación es capaz de generar conocimiento, y que no debemos pasar por alto la importancia extrema de la búsqueda de una metodología que nos permita obtener un resultado lo más fiable posible. No olvidemos que muchas veces ese registro y reproducción se van a convertir en un documento histórico que refleja el estado del petroglifo en un momento concreto, puesto que muchos de los paneles documentados en las últimas décadas ya no existen. Es preciso, por lo tanto, asegurar el registro como base esencial de trabajo en campo y al mismo tiempo garantizar que los documentos sean generados con la máxima precisión y en soportes duraderos, porque seguramente la calidad del registro de la información y el rigor en el levantamiento de los calcos sean la mejor garantía para asegurar una interpretación correcta.

Por otro lado, la documentación está detrás de cualquier medida de preservación, dado el riesgo que supone la permanencia a la intemperie de los petroglifos. El arte rupestre, es un legado cultural que, a pesar de estar protegido por la legislación vigente, está expuesto a graves alteraciones debido a los cambios en el medioambiente y, sobre todo, a las acciones directas del hombre sobre él, provocadas, la mayor parte de las veces, por simple ignorancia. Estamos de acuerdo en que necesitamos promover propuestas para que los yacimientos de arte rupestre consigan permanecer inalterados, incrementando esfuerzos para diseñar verdaderas estrategias de rescate, pensadas desde la conservación y consolidación de la roca y los motivos, y, sobre todo, promoviendo medidas de preservación prácticas que actúen en los yacimientos. Sin embargo estas medidas reales son muy difíciles de llevar a la práctica $\mathrm{y}$, a menudo, llegan tarde para un patrimonio que, debido a la gran cantidad de variables que presenta es tremendamente vulnerable y difícil de proteger. Por lo tanto, y ante la previsión que esas iniciativas de protección no se hagan efectivas, o no se lleven a cabo a tiempo, se hace imprescindible y urgente la elaboración de completos inventarios unificados bajo un mismo criterio normalizado y adaptado a la realidad de este fenómeno. La propuesta de llevar a cabo la creación de archivos sistematizados de registro, y de elaborar procesos sistemáticos de reproducción, debe plantarse como una manera de corregir lo que se ha hecho mal, o en algunos casos no se ha hecho, hasta el momento. 


\section{METODOLOGÍA DE REPRODUCCIÓN}

\subsection{Métodos de reproducción}

La reproducción de un petroglifo representa un proceso a través del cual se va a traducir y transformar lo que es visible a términos y signos concretos, es la parte más crítica del proceso de registro. Los dibujos a mano alzada y las primeras fotos en blanco y negro, forman ya parte del pasado. También el calco tradicional sobre plástico muy popular en las últimas décadas del siglo pasado, está siendo desbancado, sobre todo en el caso de la pintura rupestre y de los grabados paleolíticos, por métodos cada vez más modernos que se apoyan en los avances que el tratamiento digital de imágenes ofrece. Así, se ha producido un avance muy significativo de los trabajos de reproducción de arte prehistórico que han utilizado el tratamiento de imágenes por ordenador y han dado paso a nuevas posibilidades de reproducción mediante realización de calcos indirectos.

Pasamos a describir los distintos métodos de reproducción utilizando el criterio de dos o tres dimensiones. Aunque existen más divisiones (métodos directos o indirectos, métodos digitales o analógicos) utilizamos ésta porque creemos que es la que más influye en el resultado final y, por tanto, en la percepción que el espectador va a tener del calco.

\subsubsection{Métodos de reproducción en dos dimensiones}

\section{Dibujo a mano alzada}

Ha sido un método muy popular durante la primera mitad del siglo pasado, debido a las ventajas que presenta por ser una técnica barata y requerir poco trabajo adicional, además de evitar el contacto con la roca. Pero el dibujo presenta un problema puesto que está condicionado por la percepción del dibujante, por lo que siempre se va a obtener una versión diferente del original. Requiere que el registrador utilice su interpretación y, por tanto, un alto porcentaje de subjetividad en comparación con otros métodos. Por lo tanto en este trabajo vamos a considerar el dibujo o croquis como un método suplementario a la hora de reproducir un petroglifo, no como un método de reproducción en sí mismo.

\section{Fotografía}

Existen muchas discusiones sobre las ventajas y desventajas de la fotografía, sin embargo ha sido el método por excelencia usado para la reproducción de Arte Rupestre desde antiguo. A menudo se ha utilizado como única forma de reproducción a pesar de que, al igual que otros procedimientos, tiene sus propias limitaciones. Es, como el dibujo, una técnica no invasora, pero al contrario de ésta tiene la 
ventaja de requerir menos tiempo y habilidad. Además presenta una gran versatilidad al ofrecer varios formatos y un mayor grado de exactitud y objetividad, aunque en el caso del arte rupestre gallego, dicha objetividad se suele perder ya que, dada la poca visibilidad de los motivos, pocas veces se puede prescindir del pintado previo, lo que conlleva una interpretación subjetiva por parte del documentador. Además, en el caso de que se pueda fotografiar el grabado al natural, casi siempre va a suponer un método selectivo porque unas figuras van a destacar sobre las otras por su mayor o mejor iluminación.

La fotografía es una importante técnica de documentación gráfica pero nunca de reproducción, ya que es incapaz de capturar detalles del soporte o de los grabados, necesarios para una buena reproducción.

\section{Frotagge o «rubbing method»}

Consiste en la fricción de papel de carbón sobre papel blanco para reproducir el surco del grabado, quedando así el negativo de los motivos proyectado en el papel. Este es un método muy usado y muy eficaz en el arte rupestre escandinavo o italiano, donde la superficie de partida está muy pulida y no presenta apenas colonización biológica. En estas zonas, una vez realizados todos los frotagges se montan en laboratorio y se presentan las hojas superpuestas resultantes como una reproducción del petroglifo.

Aunque es un técnica muy valorada y empleada en petroglifos planos y con una superficie suave, particularmente en los que son producidos por incisión o piqueteado, esta metodología no es eficaz por ejemplo en el caso de las superposiciones y además puede crear confusiones entre lo que es un surco y una fractura natural. Así, los resultados deben ser interpretados por una comparación visual con el panel original después del frotagge. En otras palabras, si bien el frotagge se puede considerar a priori un calco «objetivo», va a necesitar de una ulterior interpretación para su comprensión. Además en el caso del arte rupestre gallego, se presenta el inconveniente de la rugosidad de la superficie grabada, esta rugosidad hace que el surco se distinga mal del resto de la roca, dando sólo resultado en aquellos motivos con un surco profundo. Por otro lado, a menudo los paneles se encuentran cubiertos de liquen crustáceo que no se pueden eliminar, reproduciéndose en el frotagge y disminuyendo su calidad. Por todas estas razones lo utilizaremos como un método auxiliar de reproducción.

Calco sobre plástico

A pesar de que sea un método de contacto, es, después de la fotografía, una de las técnicas más usadas. Consiste en el resultado de la transposición manual de los grabados con la ayuda de rotuladores indelebles a un plástico transparente y flexi- 
ble colocado sobre la roca ${ }^{4}$. Generalmente, en el calco se reproduce información de grabados, accidentes y contorno de la roca. Más tarde volveremos sobre este método de reproducción para describirlo de una forma más detallada.

Calco sobre fotografia analógica (Método epigráfico)

No es un método de reproducción en sí mismo, ni tenemos constancia reconocida por ningún investigador de su uso para los petroglifos gallegos. Sin embargo a juzgar por las características de algunas reproducciones es muy probable que se hicieran repasando los surcos directamente sobre una fotografía del grabado, evitando el paso de la transposición de los grabados a un plástico. Esto acorta muchísimo el proceso de ejecución, pero disminuye notablemente la calidad final al crear una perspectiva geométrica errónea.

Posiblemente esta técnica se deriva de los métodos de reproducción epigráficos, en los cuales se toma una foto en blanco y negro y se repasan los elementos por encima de ésta utilizando tinta permanente; en un segundo paso se blanquea la foto con un producto especial, permaneciendo así sólo la tinta sobre un fondo blanco, y resultando por tanto un calco. Sin embargo para que este método diera resultado, en el caso de los petroglifos, la roca tendría que cumplir varias condiciones: ser plana, caber en una sola foto y hacer ésta última desde un ángulo totalmente paralelo a la roca para evitar la distorsión. Estas limitaciones condicionan su uso enormemente, por lo menos en el caso gallego, en el cual la accesibilidad, tamaño y posición de los grabados generalmente juegan en contra.

Calco sobre fotografia digital

Consiste en generar este tipo de representaciones a partir del tratamiento digital de imágenes. Se utiliza sobre todo para reproducciones de pinturas rupestres. Presenta de nuevo la ventaja de ser totalmente inofensivo por no ejercer contacto directo con la superficie de la roca. En este método convergen dos líneas de acción. Una de ellas utiliza las posibilidades ofrecidas por las técnicas de procesamiento digital de la imagen a la documentación, estudio y conservación de la pintura rupestre, más concretamente sigue la aplicación sistemática de los métodos de clasificación de imágenes multibanda a la elaboración de «calcos electrónicos» de pinturas rupestres a partir de fotografías digitalizadas. Esta línea propone que el calco electrónico que pretende analizar la información de una manera más fiable y objetivable, y procesar datos que a simple vista son difíciles de captar. (Montero

\footnotetext{
${ }^{4}$ El calco sobre plástico en algunos países latinoamericanos se hace de una manera distinta. Se utiliza un papel de plástico adherente que se pega con facilidad a los surcos, y luego se repasan con un carboncillo los motivos grabados.
} 
Ruiz et. al., 1998). Por otra banda, el otro enfoque es aquel que parte del uso de las posibilidades técnicas pero otorga al investigador una papel activo en el proceso (Domingo y Montalvo, 2002).

Calco por medio de estación total

Consiste en tomar la información de los grabados mediante una estación total. Esto permite, en el caso de usar coordenadas absolutas, aparte de reproducir el petroglifo, georeferenciarlo ${ }^{5}$. Las coordenadas nos dan además la altura de todos los puntos. Es un sistema bastante preciso en términos generales, y es especialmente útil en el caso de petroglifos con muy pocos motivos, o cuando éstos son grandes y presentan unos límites claros y angulosos. Sin embargo, se desaconseja para petroglifos complejos, con superposiciones, motivos muy pequeños, motivos con formas redondeadas, etc. ya que para reflejar el grado de detalle necesario conllevaría una cantidad de trabajo difícil de asumir.

\subsubsection{Métodos de reproducción en tres dimensiones}

Moldes

Consiste en la reproducción directa de los grabados. Hasta unos años este método era el único capaz de producir modelos en 3D de petroglifos. Sin embargo, ha sido condenado puesto que la intervención directa en el proceso de moldeadoreproducción puede ser muy dañina para el grabado cuando se utilizan productos agresivos para reproducir los negativos de los surcos: el empleo de látex o de silicona puede producir ligeras alteraciones (descoloración, deposición de residuos materiales, etc.) por la capacidad adhesiva de los materiales. Además de esto, la elaboración de este tipo de reproducción implica la limpieza total de la superficie, por ello se necesita un barrido en profundidad de líquenes, algas y musgo, lo que aumenta el riesgo de daño para el grabado. A todo ello se une el hecho de que contamina químicamente la superficie dejándola invalidada para posibles análisis de la roca.

\section{Fotogrametría}

Es un método sin contacto capaz de generar reproducciones en tres dimensiones. Se define como "una técnica de captación y restitución que delimita dimensionalmente un cuerpo mediante fotografías tomadas desde al menos dos puntos distintos» (Matteini y Moles, 2001: 226). La fotogrametría es muy conocida por su aplicación en fotografía aérea y en registro arquitectónico. Esta tecnolo-

\footnotetext{
${ }^{5}$ Proceso mediante el cual las características de un mapa son volcadas a un sistema de coordenadas como el Ordnance Survey National Grid system (OSGB36).
} 
gía es posible gracias a la ayuda de programas para crear modelos de tres dimensiones digitales a partir una serie de fotografías. Con la aplicación de la fotogrametría digital, las posibilidades de explotación de las imágenes se amplían y se simplifican permitiendo la generación automática de modelos digitales del terreno (MDT), modelos digitales de superficies (MDS), de ortoimágenes, y la generación y visualización de fotomodelos tridimensionales. El procedimiento en campo se basa en hacer un barrido fotográfico de toda la superficie de la roca, se toman de pares de fotos con cámaras fotogramétricas desde la misma distancia y desde ángulos muy concretos. Si fotografiamos un petroglifo grande se deben tomar abundantes pares de fotos para poder solapar adecuadamente todas las áreas y crear un modelo completo de la superficie. En todos los casos se marcarán en la roca una serie de puntos de control que funcionan como referencia métrica cuyas coordenadas serán tomadas con una estación total. Para no crear distorsiones, las fotos deben ser hechas paralelas a la superficie, evitando las sombras y depósitos de agua ya que pueden interferir en los cálculos de las profundidades. Adicionalmente se debe incluir una escala en las fotos para su calibración. Para el modelaje se introducen los pares de fotografías y las coordenadas en varios software que usarán técnicas de correspondencia para obtener el calco final ${ }^{6}$.

\section{Imágenes de Realidad Virtual Photo VR}

Son imágenes interactivas de realidad virtual creadas con métodos fotográficos. Destaca en este sentido el proyecto de base de datos del Arte Paleolítico en la Región Cantábrica ${ }^{7}$, realizado en la Universidad de Cantabria. Este proyecto aglutina, imágenes esféricas IPIX para escenarios interiores, panoramas QTVR para exteriores y objetos QTVR para las piezas de arte. IPIX es una de las técnicas más avanzadas de creación de panoramas VR, permite mirar alrededor de un punto en un campo de visión que abarca $360^{\circ}$ en todas las direcciones mediante el simple desplazamiento del ratón. Un panorama QTVR es una imagen de $360^{\circ}$ visto desde un punto de una escena real o virtual, llamado nodo. Un panorama VR de un solo nodo permite mirar en todas las direcciones desde ese punto. Un objeto QTVR es una película interactiva desarrollada por Apple Computer como aplicación de su tecnología Quick Time. Utilizando el reproductor de medios podemos apreciar un objeto tridimensional desde todos los ángulos desplazando la imagen con un simple movimiento de ratón.

\footnotetext{
${ }^{6}$ Mediante este sistema se han llevado a cabo la reproducciones en 3D de importantes cuevas como la de Altamira o Lascaux.

${ }^{7}$ Base de datos multimedia Photo VR, DVD-ROM versión Windows.
} 


\section{Escaneado Láser}

Se basa en la obtención de imágenes en 3D a través de un láser escáner de alta resolución. Es uno de los sistemas sin contacto con mayor precisión para reproducir imágenes tridimensionales. Primero se proyecta una delgada línea de luz láser de $690 \mathrm{~nm}$ (nanómetros) sobre la superficie de la roca y se fotografía con una cámara CCD. El proceso es luego repetido en la superficie para obtener un conjunto de puntos referenciados que la computadora pueda transformar a un modelo tridimensional. Utiliza los principios de los modelos matemáticos de triangulación para calcular las dimensiones y la forma de la superficie. Algunos escáner tienen la capacidad de reconocer el color haciéndolo todavía más exacto. Una vez recogidos los datos se procesan utilizando distintos tipos de software, como el 3D Studio Max o el Lightwave. Además de ser un método de reproducción este sistema permite detectar nuevos grabados invisibles al ojo humano. Por otro lado presenta una gran versatilidad al poder generar imágenes tanto bidimensionales como tridimensionales. El rendimiento de este método incluye la posibilidad de hacer réplicas a cualquier escala incluyendo el tamaño real. Este método se vino utilizando hasta ahora en la reproducción de monumentos $u$ objetos arqueológicos muy concretos debido a su elevadísimo $\operatorname{coste}^{8}$ (Timothy, D et al., 2000).

\subsection{Elección de método para el arte rupestre gallego}

La reproducción de arte rupestre comenzó con simples bocetos y fotografías, que han ido progresando hacia la alta metodología tecnológica. La utilización de nuevas técnicas en la reproducción es un paso lógico en la evolución de los procesos de investigación, sin embargo, a pesar de la versatilidad que la alta tecnología ofrece, todavía no existe un método de reproducción ideal para todos los procesos ya que cada sitio y proyecto de arte rupestre van a precisar de una oferta concreta para resolver sus necesidades. En la elección de un método entran en juego una gran cantidad de factores: culturales, arqueológicos, de localización, de accesibilidad, de propiedad.También las circunstancias de la región o país van a determinar la elección de uno u otro, y por supuesto los recursos de tiempo, materiales, equipamiento, dinero, etc. Por último, el fin para el vaya a ser utilizada la reproducción será uno de los máximos condicionantes en el planteamiento del proyecto, ya que no es lo mismo realizar una reproducción dirigida a la catalogación de un petroglifo que a su puesta en valor.

\footnotetext{
${ }^{8}$ Hoy en día el mercado ofrece la posibilidad de adquirir distintos tipos de láser escáner, y su precio, dependiendo de las características concretas de cada uno, ronda los 45000 euros.
} 
La elección de la técnica utilizada se basará en éstas y otras consideraciones, por lo tanto un documentador debe de conocer tantas técnicas como le sea posible. Es más, debemos insistir en que la reproducción de motivos rupestres, debe abordarse desde diferentes ópticas y, en lo posible, no usar exclusivamente una única técnica ya que la mayoría de ellas pueden aportar aspectos que otras no contemplan. Considerando que casi todos los métodos tienen sus ventajas, deberíamos interrelacionar la elaboración de dibujos, calcos, fotografía etc., en cada proyecto excluyendo sólo los métodos que sean perjudiciales para la roca o que no posean rigor científico. Lo ideal sería hacer una comparación de los resultados de todos las técnicas en un mismo panel para determinar las capacidades y limitaciones de cada una en el caso concreto del arte rupestre de Galicia. Únicamente de esta manera, se podría reducir la subjetividad sustancialmente, consiguiendo una lectura los más completa y, aunque no objetiva, con una alta fiabilidad.

Hemos valorado las alternativas de reproducción existentes hoy en día para aplicarlas a los petroglifos gallegos y hemos analizado, al mismo tiempo, las necesidades que esta manifestación reclama. Lo ideal para la reproducción de cada petroglifo sería generar una imagen plana y una tridimensional. Evidentemente este supuesto no es realista, ya que tendría un coste en la mayoría de los casos inasumible, por ello creemos que se debe primar la reproducción en dos dimensiones puesto que, si bien, las representaciones en 3D, son muy adecuadas para las propuestas de gestión digital, como por ejemplo un GIS o una recreación virtual, se revelan poco útiles a la hora de introducirlas en soportes analógicos más sencillos y, por tanto, más usados, como puede ser una publicación o un panel informativo. Una imagen tridimensional nunca puede sustituir a una plana, ya que, aunque sea más exacta, por no asumir las distorsiones y deformaciones típicas del traslado de un espacio pseudoesférico e irregular a uno plano, no se adecua a todos los contextos.

En cuanto a la elección del método, desde el principio hemos desechado los moldes por su acción dañina para el petroglifo. Aunque las experiencias en este tema son muy variadas y cada vez se avanza más en este terreno, y a pesar de que en los últimos años han aparecido productos menos agresivos para la superficie de la roca, preferimos prescindir del moldeo directo, a no ser que se utilice en petroglifos con riesgo de inminente desaparición, o cuando esta actuación forme parte de un proyecto de difusión (réplicas) debidamente legitimado.

Hay además una serie de técnicas que también hemos descartado para la reproducción, pero sin embargo estos sí se pueden, y en algún caso se deben, utilizar en alguna parte del proceso de registro pero nunca como métodos de reproducción en sí mismos. Esto son, el dibujo a mano alzada, que se puede convertir en una ayuda 
importante para la interpretación y análisis compositivo del petroglifo gracias a la subjetividad de convenciones que conlleva, sin embargo puede carecer de fidelidad y proporción en lo que a reproducción se refiere. Lo mismo ocurre con la fotografía, de obligada introducción en cualquier proyecto por su aporte de información gráfica pero inadecuada por sí sola para la reproducción. El frotagge, en nuestro caso, va a ser usado como método de identificación y nunca como una técnica de reproducción ya que, creemos que nunca va a igualar a un calco sobre plástico ni en precisión ni en cantidad de información.

Por lo que respecta al calco sobre fotografía analógica y con estación total, ya hemos advertido de su limitación para un tipo muy concreto de petroglifos que no representan la totalidad del arte rupestre gallego.

Por otro lado, el uso del calco sobre fotografía digital plantea un problema, y es que desconocemos qué resultado puede dar en grabados, y más concretamente en los gallegos, ya que esta técnica está pensada para el caso de la pintura ${ }^{9}$ donde ha sido aplicado con relativa frecuencia, y todavía no dispone de una experiencia larga en grabados, sólo tenemos constancia del uso de este tipo de técnica en grabados paleolíticos. Si bien, en la pintura se «leen» pigmentos y colores, en los petroglifos gallegos trabajamos sobre volúmenes, y éstos son, muchas veces, más difíciles de definir. Esto no significa que no consideremos el calco a partir de fotografías digitales propicio para la reproducción de los petroglifos de Galicia. Creemos que esta técnica digital tienen amplias posibilidades de desarrollo en la reproducción en el ámbito peninsular, pero en el caso de los grabados está todavía en fase experimental y necesita un mayor desarrollo para alcanzar una efectividad real, aunque esperamos su pronta y exitosa aplicación sistemática.

En cuanto a las técnicas capaces de generar imágenes en tres dimensiones, esta metodología permite al espectador situarse en un punto activo para comprender el espacio interno del panel ya que le permite evaluar las manifestaciones rupestres en su propio contexto espacial y físico. En este caso hay un nuevo problema, la accesibilidad que esta tecnología pueda tener en nuestra comunidad. Aunque su uso es cada vez más abierto y extendido, incluyéndolas sobre todo en las bases de datos digitales, este sistema no está en absoluto generalizado, y es experimental en el caso de las pinturas y prácticamente desconocido en el de los grabados. Son técnicas bastante restringidas por necesitar de un alto grado de especialización

\footnotetext{
${ }^{9}$ Se menciona su empleo con buenos resultados en el arte rupestre nubio, levantino y sahariano, generalmente como método de comprobación y corrector de los calcos directos originales. (Montero Ruiz et al., 1998).
} 
para su correcto manejo, además de exigir un gran coste económico y de trabajo, por lo que sólo podrían aplicarse en algunos casos concretos y no como método de reproducción generalizado para todas las manifestaciones de arte rupestre gallego, por lo menos de momento. A parte de todo esto, en el caso de la fotogrametría el procesado de datos consume mucho tiempo y la realización del modelo 3D suele ser difícil y puede requerir una intervención subjetiva. Las técnicas Photo VR, se caracterizan por su alta productividad y su realidad, y por su fácil creación y obtención de archivos de realidad virtual con imágenes reales. Sin embargo, plantean un problema, estos archivos se componen de imágenes de mapas de bits, el tamaño de un archivo Photo VR puede ser enorme, y la flexibilidad del punto desde el que se observa el objeto y las transformaciones de la imagen son bastante limitadas. (Cacho Toca, 2003). Esta técnica sería muy útil en el arte rupestre gallego para mostrar la realidad virtual del entorno del petroglifo y hacernos una idea del valor estratégico y espacial de los puntos topográficos escogidos para situar los petroglifos. Sin embargo, aunque las imágenes Photo VR probablemente sean más reales estéticamente y su uso sea muy recomendable para la difusión y la puesta en valor de los grabados, no ofrecen tanta versatilidad como la fotogrametría ya que ésta, además de ser una técnica de carácter documental, es capaz de identificar y caracterizar nuevos aspectos muy difíciles o imposibles de apreciar por el ojo humano como pueden ser motivos ocultos, organización compositiva de los paneles, problemas de conservación (Vicent García et. al., 1996). Esto último es así, al menos, en el caso de la pinturas rupestres, nos queda por comprobar si la aplicación de estas ideas generales dan el mismo resultado en el caso de los grabados.

En el caso del láser escáner, la fiabilidad de las imágenes generadas no plantea ningún problema ya que tenemos constancia de su éxito en otras zonas con un tipo de grabados muy parecidos a los nuestros (Timothy, 2000). Sin embargo se suman las limitaciones que presenta su manejo en campo, donde su mayor problema, la luz, interfiere en el reflejo del láser produciendo huecos en los datos, exigiendo, por tanto, el requisito de un «bloqueo» del ambiente luminoso. Por otro lado necesita una fuente de electricidad para su uso; además presentan una gran dificultad para el transporte ya que son aparatos muy pesados, a pesar de ser considerados portátiles. A estas limitaciones menores, se suma una realmente difícil de superar, al menos de momento, y es, su elevadísimo coste. A pesar de todo esto, creemos que es el método perfectamente aplicable para la reproducción, puesto que es un sistema preciso, bastante rápido (dos pequeños paneles de aprox. $1 \mathrm{~m} \times 1 \mathrm{~m}$ pueden ser escaneados en un día de trabajo), con un consumo y mantenimiento (calibrado de la máquina) no demasiado altos, útil para generar imágenes planas y en $3 \mathrm{D}, \mathrm{y}$,

Cuadernos de Estudios Gallegos, Tomo LII, Fascículo 118, Santiago 2005. (Págs. 81 - 115) 
al igual que en el caso de la fotogrametría, capaz de identificar datos imposibles de percibir visualmente por el ser humano. Presenta, pues, unas ventajas que lo hacen revelarse como el método de reproducción del futuro a pesar de sus limitaciones, cuya superación pasa por posteriores y frecuentes aplicaciones que lo vayan abaratando y perfeccionando.

En general, en la actualidad tenemos una mayor posibilidad de acceso a las nuevas tecnologías, los programas y equipos informáticos para arte rupestre son cada vez más fáciles de manejar y probablemente en los próximos años se generalice su uso. Pero mientras este futuro no llegue y no sea aplicable a todo el conjunto de petroglifos gallegos, o, al menos, a aquellos que lo necesiten con más urgencia, tenemos que buscar un método que nos sirva para la totalidad de los casos. Estamos en un punto de estudio en que nuestro truco tiene que ser, no desarrollar prematuramente tecnologías innovadoras, pero costosas y arriesgadas, sino aplicar bien, de forma fundamentada, organizadá y seria, técnicas y metodologías corrientes. Es decir trabajar de forma sistemática y controlada, apoyando el procedimiento de análisis en los recursos en la actualidad disponibles. Sin embargo, debemos advertir que no se puede cerrar la puerta a la innovación y por ello al mismo tiempo debemos invertir en formación que dará paso poco a poco a la introducción de altas tecnologías. Por todas estas razones, nos hemos decantado por el calco sobre plástico como método general de reproducción pero siempre de forma momentánea. Hemos hecho esta elección a pesar de la tendencia actual en muchos lugares que opta generar reproducciones a partir de fotografías digitales, y siendo conscientes de sus muchos inconvenientes. Uno de ellos es el gran número de decisiones tomado por el registrador para determinar qué elementos son incluidos o no en el calco. También el derivado del propio trabajo de campo, cuyo resultado final depende no sólo de la habilidad del registrador en la colocación de los plásticos, sino de unas buenas condiciones climáticas para que éstos no se muevan en un día de viento, no se contraigan y expandan con la temperatura, o no impidan la transposición de los motivos con la lluvia. Pero el problema más importante, es que con este método es muy difícil proporcionar un resultado exacto en las superficies irregulares. Para entender ésto, hay que tener en cuenta las características del panel, aunque el calco sobre plástico pretenda adaptarse al panel, éste es frecuentemente ondulado o en tres dimensiones, y con motivos a veces situados aprovechando protuberancias de la roca. Sin embargo esta limitación es asumible, ya que es inherente a todos los sistemas de reproducción bidimensionales, donde independientemente de la técnica de los sistemas de calco siempre se va a generar una distorsión producida por el paso de una imagen original, en tres dimensiones, a otra en dos dimensiones. 
Como vemos muchos son los inconvenientes de su uso, y, sin duda, en su elección ha jugado un papel importante un factor en negativo: la inaccesibilidad momentánea a otras técnicas más innovadoras y más exactas. Pero también ha sido muy importante el hecho de que es un sistema que genera imágenes planas con una ventaja fundamental: que el documentador trabaja en contacto directo con la superficie del panel, lo que lo convierte en un método adecuado para petroglifos apenas visibles. El arte rupestre gallego se caracteriza muchas veces por la difícil percepción de las figuras, siendo necesario discutir, determinar y registrar todas las cuestiones en campo. Como ya dijimos, el calco es hecho sobre un plástico transparente con las hojas en contacto directo con la superficie de la roca. Este contacto directo con la superficie de la roca y el funcionamiento manual es la única manera de reconocer algunas figuras a la espera de que se desarrollen otras posibilidades de observación para reconocer las figuras, las superposiciones, y las alteraciones de la roca en la superficie grabada.

\section{EJECUCIÓN DEL CALCO DIRECTO SOBRE PLÁSTICO: FASES DE TRABAJO}

Podemos dividir el proceso de elaboración de un calco en dos fases de trabajo principales en campo y en gabinete:

\subsection{Elaboración del calco en campo}

\subsubsection{Delimitación del área grabada}

El primer paso para ello es la limpieza en profundidad del petroglifo, para lo cual hay que eliminar líquenes, tierra húmica, algas, vegetación superior, etc. o cualquier otro agente depositado sobre el petroglifo que pueda perjudicar la observación de los grabados. Si bien la eliminación de algas y musgo es relativamente fácil, la limpieza de los líquenes es el paso más complicado. Casi la mayor parte de las alteraciones que sufren los petroglifos gallegos están provocadas por la colonización de líquenes, así, si bien parecen ser el agente más intensamente degradante para la roca, su eliminación se ve limitada por una doble problemática. Por un lado, provocan una profunda acción meteorizadora, y producen efectos negativos sobre la roca a largo plazo desde el punto de vista mecánico (penetración de rizoides) y químico (retención de agua, producción de gases, secreción de sustancias químicas, etc.), pero provocan, por otro lado, a corto plazo, una protección frente a otros agentes de alteración. Además, al proceder a su limpieza se puede dañar la roca, ya que, al eliminar los rizoides incrustados a través de los cristales de la roca se dis- 
grega la parte superficial de ésta, dejándola abierta a la penetración de otros agentes de alteración (Carrera, 1996). Así pues, sólo podemos proceder a la eliminación de los líquenes folíaceos que son aquellos más superficiales, nunca debemos desproveer a la roca de los líquenes crustáceos, es decir los que se encuentran firmemente incrustados a la roca. También se procederá a la limpieza de fisuras, diaclasas o concavidades colonizadas por vegetación, así como al despeje de los márgenes de la roca.

La finalidad de esta limpieza es facilitar la visión de los grabados y por otra parte dejar al descubierto posibles grabados ocultos, y sólo se hará cuando sea la única forma de observar los grabados y delimitar las figuras. Esta operación se realizará con sumo cuidado para no dañar la superficie de la roca, y no provocar efectos negativos en la misma. Nunca se emplearán materiales que puedan dañarla o erosionarla, como agentes químicos agresivos (p. ej ácidos); ni mecánicos, como raspadores de metal que pueden afectar a la pátina. Se conocen productos para la eliminación de líquenes pero están prohibidos por el posible riesgo que conllevan a largo plazo. El uso de instrumentos blandos de madera, como espátulas de cocina, o de plástico, y de esponjas para quitar la capa más gruesa de líquenes y musgo, en la mayoría de los casos es suficiente y muy efectivo. Todo lo que no salga con esto se debe dejar, puesto que su eliminación podría dañar seriamente el petroglifo. Después de esta limpieza se procederá a un barrido profundo de la superficie, con un cepillo de cerdas blandas, para eliminar los residuos que queden, si hay mucha suciedad en la superficie se puede humedecer el cepillo en agua.

\subsubsection{Observación e identificación de grabados}

Es imposible, hacer un calco de algo que no podemos definir de una manera exacta, así que el siguiente paso, por muy obvio que parezca, es observar detenidamente e identificar los motivos. Tenemos que reconocer perfectamente todas las figuras grabadas en la superficie de la roca, ya que su reconocimiento completo es la base para una reproducción correcta, y éste, a su vez, es el resultado de una buena observación. Lo mas importante en este proceso de identificación va a ser la experiencia y habilidad del arqueólogo, pero en muchos de los casos ésta por sí sola no será suficiente y se habrá que ayudar de otros métodos que explicaremos más abajo. En los casos donde se presenta una superficie no demasiado dañada ni erosionada se pueden identificar las figuras con un porcentaje alto de fiabilidad. Sin embargo, la mayoría de las veces los motivos se encuentra alterados, presentan un surco muy poco profundo o están superpuestos, es en estos casos cuando se hace más dificultoso reproducir el panel original. 
Una vez limpia la superficie el paso para ejecutar una buena identificación de los motivos grabados es el examen del petroglifo, identificando y delimitando los grabados. Para ello se van a utilizar distintas condiciones de luz:

- Lectura de grabados por medio de luz natural a distintas horas del día. En este punto debemos pararnos y establecer las mejores condiciones de luz pormenorizadamente, teniendo en cuenta que la buena visibilidad de los grabados dependerá de la intensidad de la luz, de la procedencia, del ángulo, y de la climatología de ese momento.

Al igual que para la toma de fotografías, sin duda los mejores días para la observación de grabados son los despejados con sol, son también especialmente indicados los días de lluvia, y los días que los suceden, especialmente si éstos son soleados, ya que el petroglifo se encuentra mojado e iluminado al mismo tiempo. No son muy indicados los días nublados. En cuanto al momento del día, las mejores horas son aquellas en las que luz sea proyectada con un ángulo cerrado sobre los grabados, esto es, las primeras y especialmente las últimas horas. En estos momentos gracias a la luz rasante los objetos son iluminados de forma lateral proyectando sombras más contrastadas y alargadas. Cuando la luz se proyecta verticalmente o formado un ángulo abierto sobre los grabados se dificulta su lectura, esto es, en las horas intermedias del día, sin embargo se pueden apreciar otras informaciones como distintas texturas o procesos de alteración. Por lo tanto, aconsejamos siempre que sea posible la revisión de los grabados a todas horas del día, ya que una nunca es excluyente de la otra.

La posición idónea para examinar los grabados es siempre situándose frente al punto de donde procede la luz .

- Examen del petroglifo con luz artificial. Especialmente indicado para petroglifos con dificultades de lectura que tengan figuras con surcos poco profundos o claros, ya que la iluminación artificial ayudará a interpretar diseños dañados o erosionados. Para ello se pueden utilizar cualquier tipo de foco autónomo con una mínima potencia. Sin embargo se recomienda el uso de linternas alógenas situándolas de modo que proyecten una luz rasante sobre los grabados. Sin duda es uno de los mejores métodos para la identificación de motivos, en muchos caso sólo una luz artificial debidamente orientada es capaz de clarificar algunos de los motivos más erosionados, (Figura 1). 


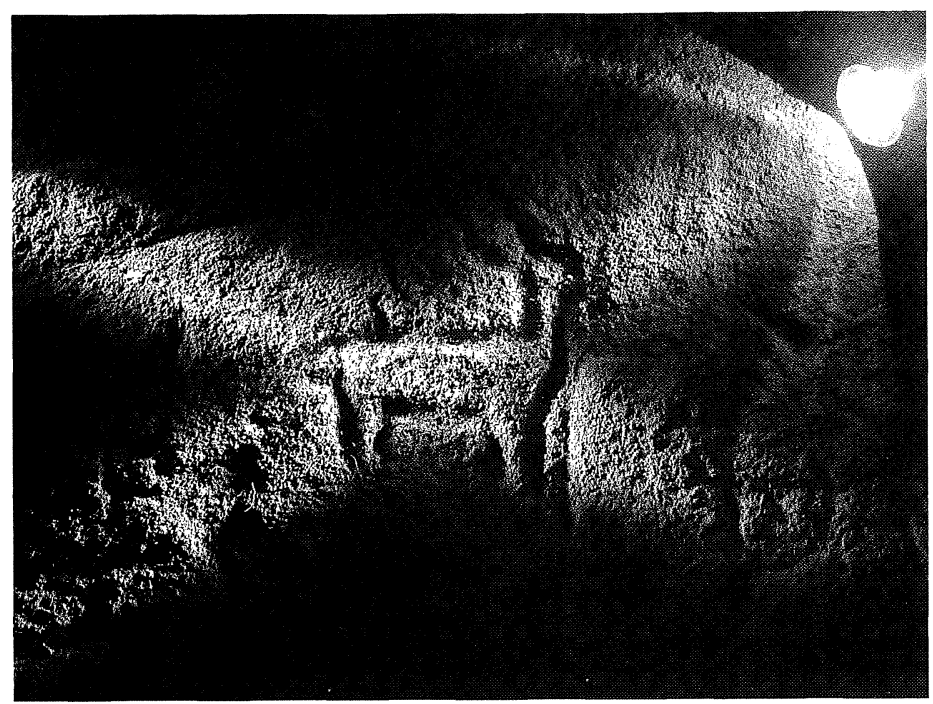

Figura 1.- Motivo iluminado artificialmente.

\section{- Otros procedimientos complementarios.}

Debemos advertir que en la mayoría de los casos con la observación utilizando estos dos condiciones de luz es suficiente, pero si se considera necesario también podemos introducir otras técnicas de como es la lectura mediante el efecto luminoso de un espejo, para esto se necesita un espejo con unas dimensiones mínimas $40 \times 40 \mathrm{~cm}$. Se colocará el espejo cara a la fuente de luz y se proyectará la luz que produzca sobre el grabado, colocándose una sombra para que no cree una luz demasiado brillante. Produce unos buenos resultados especialmente en días soleados.

Ya hemos advertido antes sobre las limitaciones del frotagge, pero en algunos casos muy concretos su uso puede ser adecuado. Los medios necesarios son papel verjurado de color blanco, no muy grueso pero resistente; cinta adhesiva para fijar el papel a la roca, también se pueden utilizar piedras o cualquier otro objeto pesado; y papel carbón negro o azul oscuro del que se usa en tareas de duplicación mecanográfica. La técnica es dividir el panel en rectángulos con un sistema de referencia, y colocar los trozos de papel blanco del mismo tamaño. Para realizar esta técnica con éxito la superficie de la roca debe de estar lo más limpia posible puesto que cualquier agente ajeno a la roca se proyectará en el frotagge. Se cubrirá la roca con el papel, y se procederá a la fricción con el carbón que también debe estar completamente 
estirado para no hacer arrugas en el papel, luego para dar mayor contraste cromático a los contornos de las figuras se puede pasar un manojo de hierba verde por encima del papel y, finalmente, para fijar el pigmento es útil aplicar, una vez finalizado, laca u otro producto aerosol con efecto adherente. Una finalizado el frotagge es necesario comprobar el resultado con la superficie de la roca.

También queremos señalar la importancia del uso de la fotografía como herramienta de extraordinaria utilidad para la lectura de los petroglifos. Tanto en la fotografía tradicional como en la digital se pueden observar grabados y detalles de la roca que de otro modo serían difíciles de ver. Por otro lado, no debemos olvidarnos de un método que con determinados tipos de superficie puede dar también muy buen resultado, siendo un excelente técnica de identificación auxiliar por su sencillez y accesibilidad, el tacto . Éste sirve muchas veces para corroborar la existencia de surco o las irregularidades en la roca que a veces sólo son observables en fotografía o bajo determinadas condiciones.

Debemos señalar que con cualquier método de observación que utilicemos, al mismo tiempo que vamos reconociendo las figuras iremos repasando tenuemente el surco con una pintura especial en barra, de cuyas características hablaremos más abajo, con el fin de tener todas las figuras debidamente marcadas para el paso siguiente.

\subsubsection{Pintado del petroglifo}

Mucho se ha discutido de la conveniencia o no de pintado de los petroglifos. La cuestión de si se debe o no usar pintura, en concreto tiza, en la documentación de arte rupestre ha sido ampliamente debatida entre los investigadores internacionales. De estos debates surgió un código de ética que rechazaba completamente el uso de sustancias químicas en los grabados, aunque fue modificada posteriormente, tanto por la agresión física que puede conllevar como por el riesgo de condicionar la realización de análisis posteriores. Otro de los argumentos es el que se relaciona con la subjetividad de este método al interferir en la forma original del diseño, ya que se impone la interpretación del investigador. Sin embargo aunque si bien la primera razón es óbice para el pintado de nuestros petroglifos, no lo es la segunda. Debido a la nula visibilidad en la mayoría de los casos y a la poca definición natural de los bordes de los surcos, la realización de un calco sin pintura provocaría un índice de duda, y por tanto, de interpretación, mayor por parte del registrador al no tener suficientemente claros los contornos de las figuras menos profundas, y generaría así un resultado de menor calidad. 
La finalidad del pintado es que todas las figuras se hagan visibles creando un contraste entre el surco y la superficie no grabada para obtener una imagen nítida de las figuras. Debemos de reconocer que mientras las técnicas tradicionales, como es el calco, estén en uso, el pintado es imprescindible, por lo que tenemos que buscar la solución menos dañina para los grabados. Esto es, una pintura que cumpla tres requisitos: que ofrezca unas condiciones de permeabilidad y reversibilidad altas, que presente una nula agresividad en la roca, y que cree un contraste óptimo con el resto de la roca.

Sin duda la pintura más comúnmente usada en todo el mundo es la tiza $(\mathrm{CaC} 03)$, o bien, usándola sola para remarcar los grabados, o bien, mezclándola a partes iguales con agua para pintarlos. Sin embargo, al ser un producto alcalino, produce un efecto químico sobre la roca actuando sobre la microflora y provocando la desaparición del liquen. Esto, como advertíamos anteriormente, deja sin microorganismos la superficie de la roca, lo que puede crear a largo plazo problemas de desprotección para la misma. Teniendo en cuenta esto hemos buscado otras alternativos como pueden ser las harinas de maíz y de trigo mezcladas a partes iguales con agua. Estos dos productos aunque en un principio puedan parecer totalmente inocuos para la roca al ser naturales, su uso evidenció que pueden producir la aparición de nuevos tipos de liquen en las zonas donde se aplica, aunque se haga una buena limpieza de la roca después de su uso. Ante todo esto, recomendamos el uso de dos clases de pinturas:

Pigmentos naturales inorgánicos, para su aplicación necesitan ser antes diluidos en agua. La proporción variará según la fijación que le queramos dar a la pintura. Dependiendo de cada color proceden de un mineral distinto. Hemos experimentado con dos tipos: con la sombra natural y con el ocre. El primero es tierra natural, de composición similar a la del siena, pero de mayor contenido en manganeso, tiene un color pardo oscuro, con tonalidades que varían del verdoso al amarillento al violáceo, y no es totalmente opaca. El ocre es arcilla coloreada por hierro que presenta tonalidades amarillas y apagadas, es una pintura opaca.

Pinturas pastel, son barras de pastel molidas. La composición es pigmento con creta precipitada y goma de tragacanto (sustancia generada por una planta de la especie astrágulus). Según la fuerza del aglutinante de cada uno de los pasteles, obtendremos una mayor o menor permanencia de la pintura sobre la roca. Los colores utilizados fueron el blanco y el rojo, el pigmento del primero es creta precipitada y la fuerza del aglutinante media, dura intacto varias llu- 
vias. En cuanto al rojo, el pigmento es bermellón y la fuerza del aglutinante media-fuerte. Destaca menos que el anterior y dura más tiempo ${ }^{10}$.

Para realizar los calcos, nos decantamos por éste tipo de pinturas, ya que no suponen ninguna agresión para la roca o grabados, al ser sus componentes totalmente vegetales y/o minerales. Cualquiera de ellos es óptimo, las pinturas pastel en su tono blanco destaca más que los pigmentos naturales, pero sin duda estos últimos dan al grabado un aspecto más natural, además de suponer una menor permanencia en la piedra.

Cada documentador debe elegir y proponer el tipo y color de pintura más adecuada para el fin que busca. Una vez elegido el colorante, se procederá al pintado de los motivos con el método conocido como «sueco», que es aquel que resalta sólo los surcos. Hay registradores que usan otro tipo de método, como es el de resaltar las partes de la roca que no están grabadas con alguna sustancia como pueden ser pintura o polvos de talco, dejando solamente los surcos intactos. También en alguna ocasión, como alternativa se han rellenado los surcos de arena para hacerlos visibles. Sin embargo, y siempre que utilicemos una pintura no perjudicial para el petroglifo, creemos que estos modo de resalte son más dificultosos a la vez que menos precisos.

\subsubsection{Colocación del plástico}

El material necesario para la elaboración de un calco es plástico para soporte (plástico transparente semirígido), cinta engomada o plastilina para fijar el plástico a la roca, y rotuladores indelebles de distintos colores.

Se coloca el plástico sobre el petroglifo en contacto directo con la superficie. Éste es uno de los pasos que más van a influir en un buen resultado por ello debemos insistir en la correcta colocación del plástico de forma que quede bien tirante sin ningún tipo de arruga, además debe quedar bien fijo, procurando que no se mueva hasta que hayamos acabado. El tamaño de las hojas plásticas evidentemente variará según las dimensiones de la roca, no obstante proponemos un tamaño estándar con el que trabajar holgadamente en gabinete de 700x1500 cm. Para la correcta ejecución del calco es conveniente dividir la roca en sectores y que a cada sector le corresponda un plástico. Siempre se comenzará por un extremo con el fin de llevar un cierto orden a la hora de colocar y numerar los plásticos. En caso de

\footnotetext{
${ }^{10}$ Información facilitada por Yolanda Porto Tenreiro, restauradora del Laboratorio de Arqueoloxía da Paisaxe, Instituto de Estudios Galegos Padre Sarmiento.
} 
que se utilice más de un plástico, siempre se numerarán y se insertarán una serie de puntos de referencia con el objeto de tener ubicado cada plástico con relación a los demás, una vez sean movidos las hojas. Para hacer esto se superpondrá una parte del plástico con el siguiente (unos diez centímetros), colocando en la plástico inferior una marca numerada que repasaremos en el plástico superior. Si se considera necesario se puede poner la misma marca con pintura en la roca por si fuera preciso volver a colocar el plástico en el mismo lugar, y también para asegurarse de que durante el proceso de calcado el plástico no ha sido movido. Se recomienda dibujar en cada plástico un mínimo de dos marcas que se distinguirán con un número (el número de plástico que le corresponda) y con una letra. Con esto conseguiremos identificar toda la representación y casar casi milimétricamente unos plásticos con otros en gabinete. Cuando el petroglifo sea de grandes dimensiones es muy útil hacer un croquis de la colocación de los plásticos.

\subsubsection{Perfilado de las figuras sobre el plástico}

Se realiza con rotuladores indelebles, utilizando una convención de diferenciación por medio de color y/o trazado. Se trata de encontrar un equilibrio entre la información útil y el exceso de información, sin embargo dependiendo del proyecto se necesitará un mayor o menor cantidad de datos. Por ello se distinguen varios tipos de elementos, los elementos básicos que deben de reflejarse en todos los calcos son los grabados antiguos y recientes; contorno de la roca; accidentes naturales de la roca: grietas, protuberancias, piletas, diques, etc. Es muy útil fijar desde un principio una convención de colores para cada uno de los motivos que se repita en todos los calcos para no inducir a errores. Nuestro estándar es el negro para los grabados antiguos; el azul para los grabados modernos; el azul con rayas para los grabados antiguos repicados; el rojo para los accidentes morfológicos de la roca: grietas, diques, pías o protuberancias de la roca, indicando cuando proceda de qué tipo de accidente se trata; y el verde para el contorno de la roca. Es conveniente utilizar la doble línea para repasar las grietas, sin embargo en los casos en que sean muy estrechas bastará con la línea simple. Se utilizará la línea discontinua cuando los límites de los grabados, contorno de la roca etc. no sean claros o estén tapados.

Se repasa el contorno del surco con el indeleble del color establecido utilizando una línea que perfile el contorno de surco (Figura 2). En determinadas zonas como son las de Valcamónica (Italia) y la de Tanum (Suecia), para reproducir las figuras se realiza un entrelazado que nos permite indicar, por un lado, la profundidad del surco y, por otra, delimitarlo, ya que un surco nunca sigue una línea definida sino que se adapta a la granulometría de la roca. Cuando nos encontramos con un surco más profundo se utiliza un entrelazado más denso, que se va 
haciendo más separando a medida que el surco decrece en profundidad. Esto crea un efecto visual en el calco de manera que los grabados aparecen más claros y más oscuros según su profundidad. La utilización de este método, al menos en Valcamónica, tiene que ver con la técnica de grabado utilizada, el piqueteado. Así, es probable que se use el entrelazado para reproducir los desniveles provocados por ésta técnica.

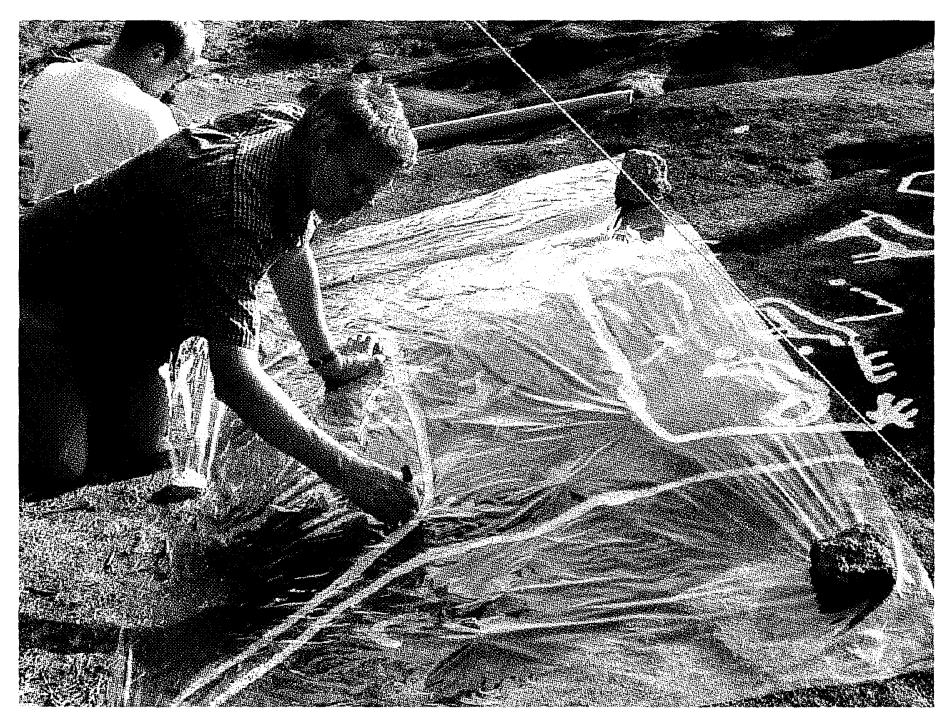

Figura 2.- Perfilado de las figuras.

Sin embargo en el caso gallego, puesto que la técnica de grabado es otra, y con el fin de agilizar y simplificar el proceso, optamos por el sistema de contorneado de las líneas básicas del perfil. Para reseñar en campo la profundidad del grabado se utiliza dentro del surco dibujado, una escala relativa de profundidades en la que 1 es menos profundo, 2 medio y 3 más profundo. Esto nos servirá posteriormente en gabinete, para advertir al observador de las diferencias de profundidad, lo que permite en la mayoría de los casos una mayor definición del motivo.

Cuando finalicemos conviene repasar visualmente todos los plásticos para asegurarnos de que no falta ningún dato, cuando lo hayamos hecho, en el borde de cada hoja colocaremos el número de plástico que le corresponda, el norte geográfico, y dibujaremos la medida de $50 \mathrm{~cm}$ para disponer más tarde de una escala. Si el proceso ha sido correctamente aplicado obtendremos una serie de hojas plásticas con partes coincidentes que nos permiten montar la totalidad del petroglifo. 
Estas hojas no van poder ser manejadas en su escala original por ello se planteará la necesidad de reducirlos a una escala conveniente.

\subsection{Tratamiento de calcos en gabinete}

Antes de realizar cualquier proceso de tratamiento en gabinete es necesario un paso previo, el traspaso del calco a un formato digital, para lo cual se hacen fotografías digitales de la totalidad de las hojas de plástico. El primer paso para ello es fijar la/s hoja/s a una superficie blanca vertical (una pared, un cartón blanco, etc.) debidamente montadas, superponiendo las partes comunes de los plásticos, de manera que todas las figuras coincidan correctamente. En el caso de que el petroglifo tenga unas grandes dimensiones y se disponga de un gran número de hojas imposible de desplegar al mismo tiempo, se fotografiarán juntas el mayor número de hojas posible puesto que cuantas menos fotografías tengamos, mas exacto será el proceso al no tener qué unir más tarde las partes comunes de las fotos.

Para la toma de las fotografías se debe buscar un punto desde el cual se pueda apreciar con nitidez cada figura y desde el que entre la totalidad de las hojas de plástico. Es conveniente que la zona donde se coloca las hojas esté libre de la incidencia directa de la luz, ya que ésta crea muchos brillos en el plástico que disminuyen la calidad del resultado final, por eso se recomienda una zona interior con luces moderadas. Las fotografías se han de realizar con un jalón o escala, y siempre se debe usar trípode ya que, en el caso de que haya que hacer más de una fotografía es doblemente beneficioso puesto que servirá para fijar la cámara en un punto una distancia concreta e igual para todas las hojas de plástico.

Existen dos formas de tratar las hojas de plástico en gabinete:

1. Proceso manual de reducción a escala manejable por medio del escaneado. Después de la obtención de la fotografía del calco, en el caso de que haya más de una fotografía se procede a su unión para obtener una sola imagen del calco. Esto se hará sobreponiendo las partes comunes de las fotografías. Una vez realizado esto, sobre una mesa de luz, se procederá al calcado sobre papel vegetal blanco de los elementos representados con rotuladores muy finos, a este mismo papel también se hará la transposición de la escala y del norte geográfico. Con esto obtendremos el calco a una escala manejable, podremos escanear el calco para pasarlo a formato digital lo que nos permitirá ampliar o reducir su escala, y hacerle cualquier tipo de adicción. Este proceso es difícil de realizar en petroglifos de gran tamaño puesto se necesitaría un escáner de grandes dimensiones. 
2. Tratamiento digital para la el procesado del calco, para esto utilizamos el programa Adobe Photoshop ${ }^{12}$. Las fases para el procesado digital son las siguientes:

El primer paso es la unión de todas las fotos de los plásticos. El proceso, evidentemente, será más sencillo cuanto menor sea el tamaño del petroglifo y por tanto el número de plásticos, también será más preciso porque si hay pocas fotografías o una sola, se acumula poco o ningún error a la hora de unirlos. Hoy en día existen cámaras en el mercado que incluyen programas de ensamblado automático de fotos, sin duda, ésta es una ventaja a la hora de realizar un calco ya que ahorra mucho tiempo y esfuerzo. Si no disponemos de este programa podremos unir las fotografías «manualmente» en Photoshop, a continuación explicamos el procedimiento paso por paso.

- Se abre en Photoshop un archivo nuevo desde el menú principal (Archivo/ Nuevo) dándole un nombre (p. ej. Calco). El tamaño del lienzo se aumentará en esa misma pantalla. Podemos empezar dándole un valor de 500 píxeles de ancho y altura, que va a variar, lógicamente, en función del tamaño de las fotos. Siempre que necesitemos ampliar el lienzo podremos hacerlo en el menú principal: Imagen/Tamaño del lienzo.

- Importamos las fotos al archivo calco, la mejor opción es importar una por una. Para realizar esto debemos ir al archivo de Photoshop donde tenemos la fotos guardadas, y allí se seleccionará la foto con la herramienta seleccionar de la barra de herramientas y copiamos en Edición/Copiar. Una vez hecho esto, volvemos al archivo calco y pegamos en Edición/Pegar, y hacemos la misma operación con el siguiente plástico. Cada plástico que insertemos va a ser reconocido por el programa como una capa. Es conveniente que empecemos a ensamblar las imágenes desde el momento que tengamos pegadas dos fotos, independientemente del número de plásticos-fotos que haya. (Figura 3).

- El ensamblado de las imágenes es un paso hasta cierto punto complicado, ya que necesitamos que las figuras casen correctamente desde el primer plástico hasta el último, de lo contrario se acumula error. Para engarzar dos imágenes lo primero que debemos hacer es montar las partes comunes de los plásticos, para ello vamos a dar menos opacidad (en la paleta capas) al plástico que deba ir encima, con ello conseguimos hacerlo transparente para ver

${ }^{1}$ Nuestra versión del Adobe Photoshop es la 7.0. 


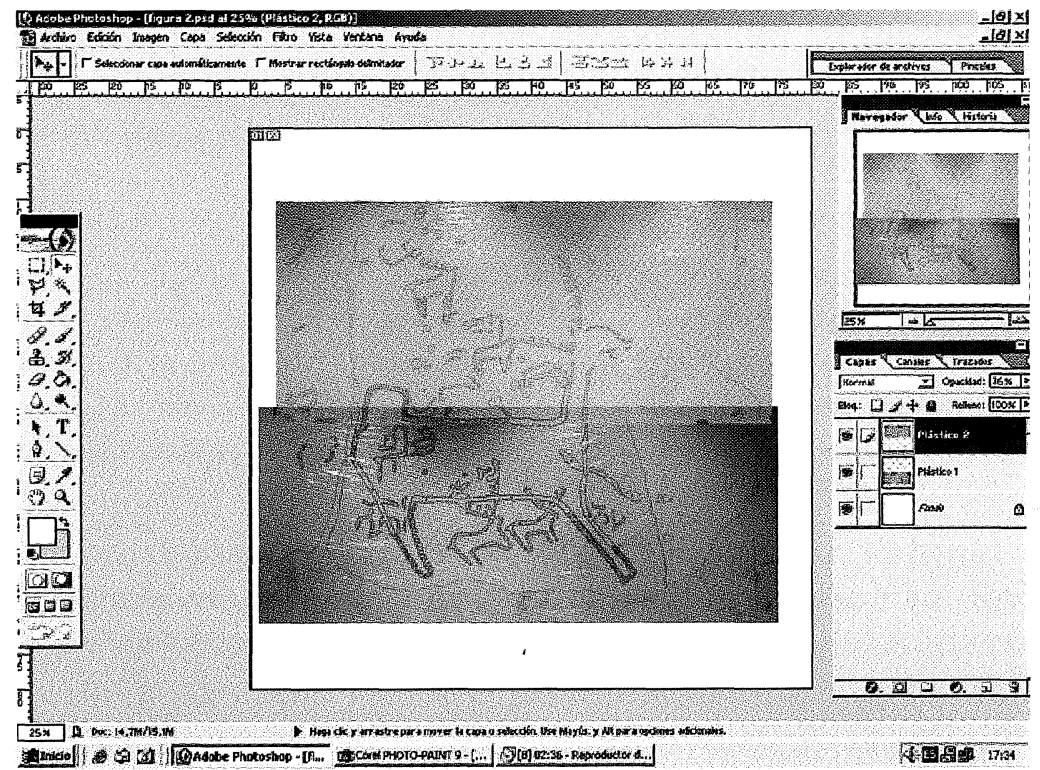

Figura 3.- Proceso de engarzado de las imágenes.

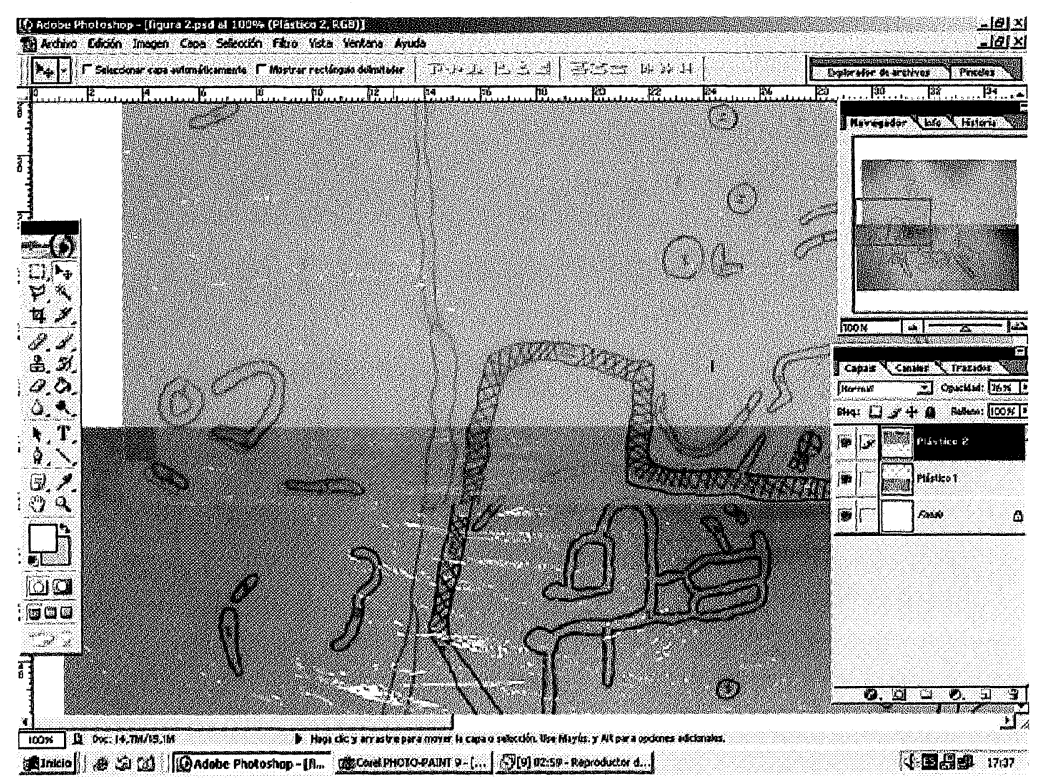

Figura 4.- Distorsión en la unión de dos imágenes. 
y superponer las figuras unas encimas de otras. Para mover el plástico utilizamos la herramienta mover de la barra de herramientas. Es muy importante que estemos en la capa que corresponde ya que si no podemos mover un plástico que no deseamos.

Si en algún momento queremos cambiar el orden de los plásticos, es decir que el que figuraba abajo lo haga ahora arriba, no tenemos más que ir a paleta capas, situar el ratón sobre la capa presionar el botón izquierdo, y llevarlo encima de la capa elegida. Si queremos reducir o aumentar el tamaño de la imagen vamos a Edición/Transformación /Escala. Algunos de los plásticos casan perfectamente, pero otros presentan error en algunas de sus partes (Figura 4), así que habrá que corregir todos los fallos que las figuras presenten en su unión. Algunas veces se consigue aumentando o disminuyendo el tamaño, pero otras esto no es suficiente y debemos rotar la imagen. Para ello debemos ir a Edịción/Transformación/Escala o Edición/Transformación/Rotar hasta que queden perfectamente engarzadas (Figura 5). Una vez que estén engarzados los plásticos es conveniente bloquear las capas que estén listas con el fin de evitar movimientos indeseados de éstas, para ello iremos a paleta capas y utilizaremos la herramienta candado.

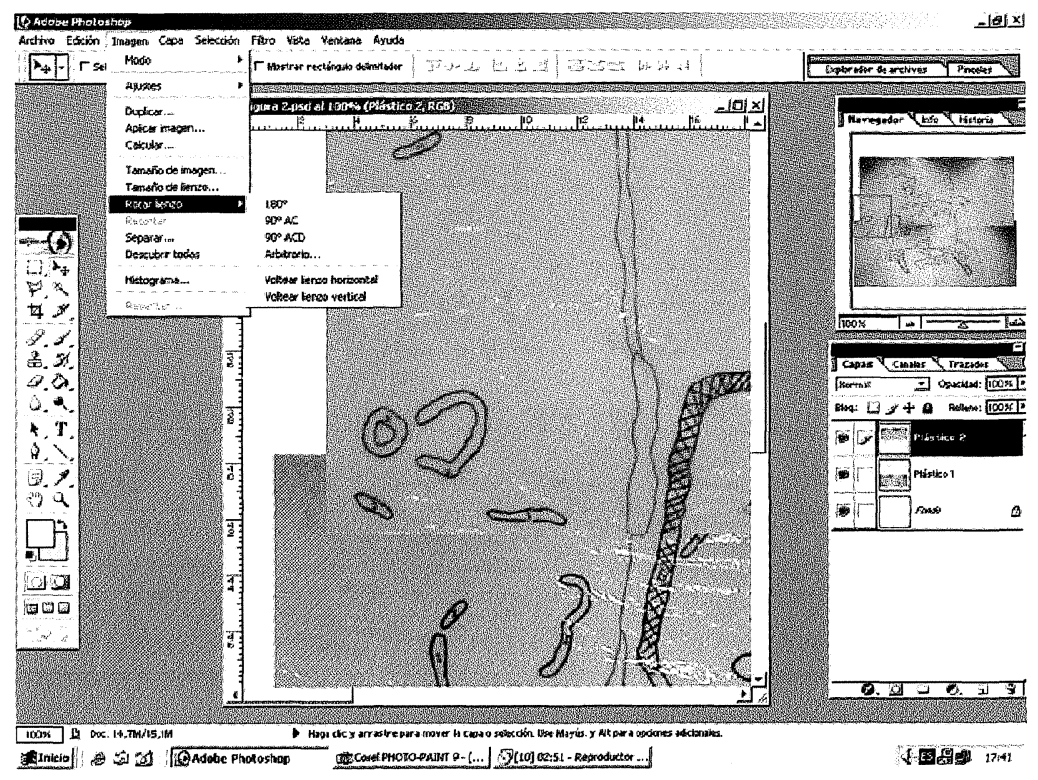

Figura 5.- Figuras correctamente ensambladas. 
- Una vez introducidas todos los plásticos y engarzados correctamente nos quedará todos en una sola imagen en la que todas las figuras unen sin ninguna o con muy poca distorsión (Figura 6). Cuando este proceso acabe es conveniente que todas las capas se fusionen en una sola, esto se hará en menú principal en Capa/Acoplar imagen.

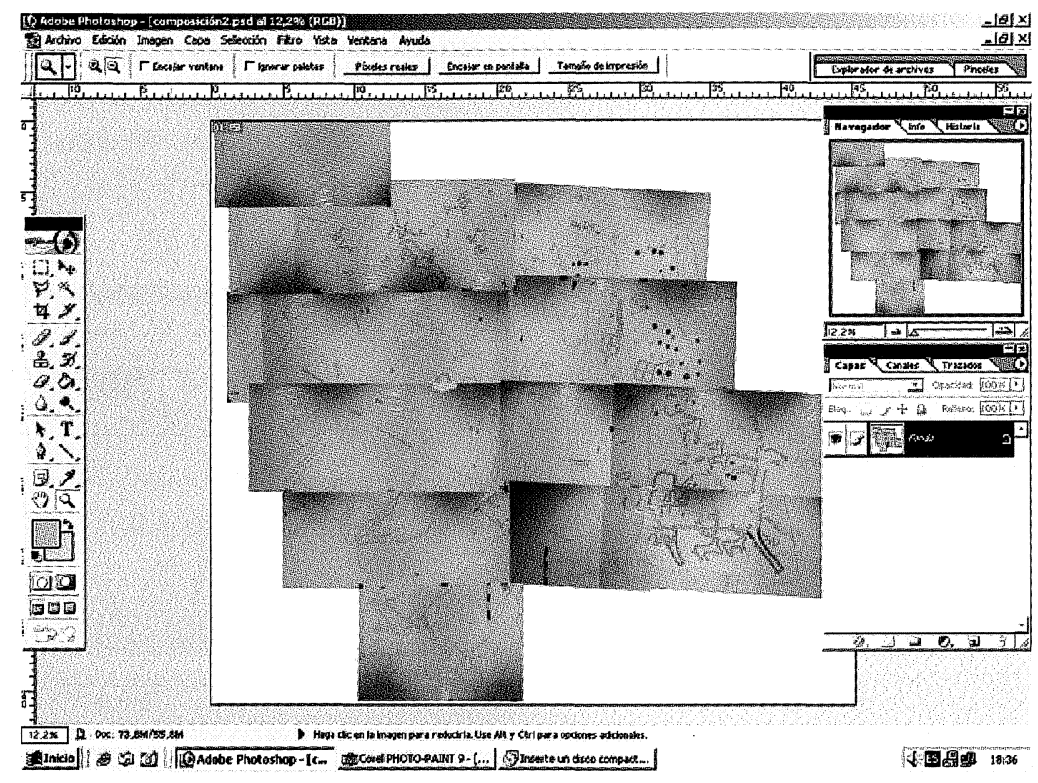

Figura 6.- Imagen resultante de la unión de todas las fotos.

Una vez hecho esto entramos en la segunda parte del proceso donde es necesario sacar de esta imagen la información relevante y desechar lo que no nos sirva. Esta información útil la colocaremos sobre un documento en blanco donde destaquen las figuras que nos va a servir de soporte para el calco definitivo. Así pues lo primero que vamos a hacer es crear un nuevo documento en Archivo/ Nuevo.

- Empezaremos por repasar los contornos, las grietas, y otras características naturales de la roca como pueden ser rebajes, protuberancias, diques... (Figura 7) En nuestro caso también repasamos los motivos modernos y los motivos antiguos repicados. Para cada unos de ellos vamos a crear una capa en el menú despegable de Paleta capas/ Nueva capa y le vamos a dar el nombre que corresponda. Para repasar el contorno utilizamos herramienta pincel con el color deseado, en el menú superior al elegir la herramienta 
pincel podemos elegir el grosor deseado para el pincel y en la barra de herramientas tenemos la opción de cambiar el color. Siempre que nos equivoquemos podemos ir a herramienta borrador y corregir el error, o bien en menú principal Edición/ Paso atrás o Deshacer.

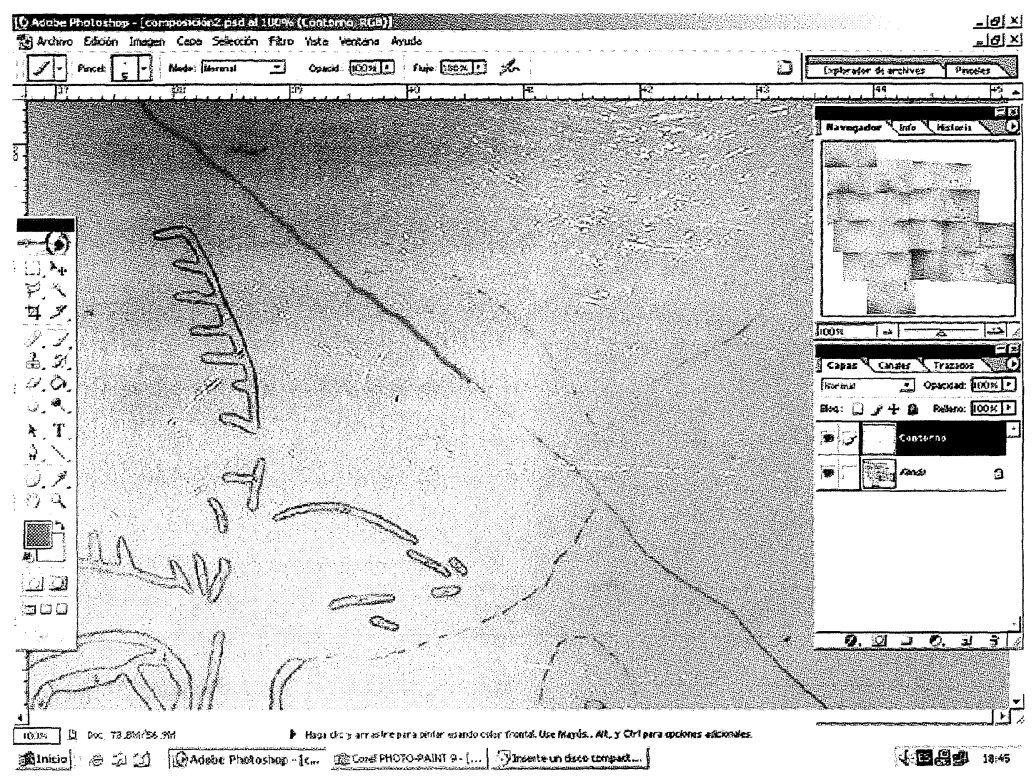

Figura 7.- Contorneado del límite de la roca con el pincel.

Antes de llevar todas las capas a un documento en blanco, necesitamos buscar un elemento común dentro del calco para referenciar y posicionar cada una de las capas que vayamos insertando con relación a la anterior, puesto que no las vamos a insertar todas al mismo tiempo en el nuevo documento. No es muy aconsejable utilizar cualquiera de los elementos del calco puesto que al borrar podríamos distorsionar el resultado, así que vamos a crear un referente nuevo, para ello vamos a herramienta rectángulo y creamos una forma en cualquier lugar del calco. Una vez contorneados todos estos elementos los seleccionamos con la herramienta varita mágica de la barra de herramientas seleccionando también el rectángulo que previamente habíamos creado, lo pegamos en el nuevo documento (Figura 8) y vamos haciendo lo mismo con los demás. El programa por defecto nos va creando una capa por objeto que introduzcamos, nosotros le podemos dar el nombre exacto del elemento al que se refiere (contorno, grietas...). 


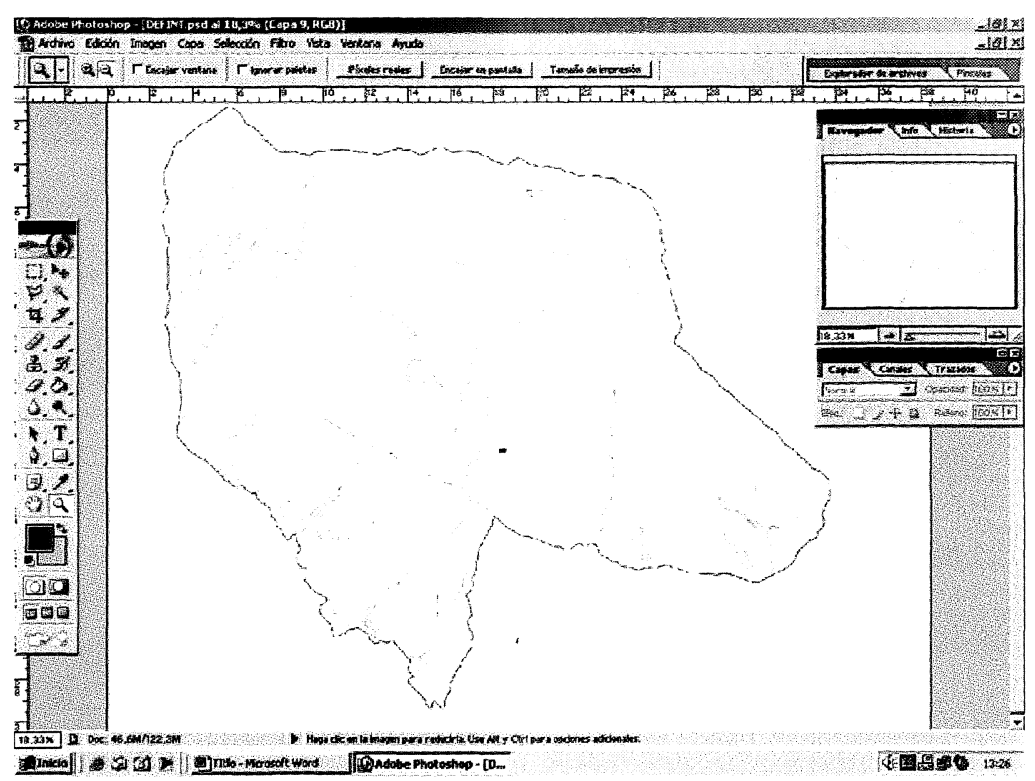

Figura 8.- Elementos insertados en el nuevo documento.

- Para los motivos o bien podemos utilizar este sistema de contornado previo, o bien podemos utilizar el procedimiento de la varita mágica. Con la herramienta varita mágica vamos seleccionando el interior de cada una de las figuras. Para ello, es muy importante tener activada la casillas de «contiguo» y «usar todas las capas», que aparecen en el menú superior al elegir la opción «varita mágica». Cuando las figuras no tengan un contorno bien cerrado, este método nos puede dar problemas, por lo tanto es muy importante en campo cerrar todas las figuras con el rotulador, de lo contrario la varita nos puede seleccionar algo indeseado, si esto ocurre deberemos bajar el nivel de tolerancia que encontraremos en el menú superior, para que nos seleccione poco a poco un espacio muy concreto. En este punto es cuando empezaremos a diferenciar los surcos en función de su profundidad. Escogeremos por cuáles queremos comenzar, y seleccionaremos con la varita mágica el interior de todos los surcos de esa profundidad (Figura 9), a veces una misma figura tiene distintas profundidades por lo que seleccionaremos sólo una parte. Cuando tengamos todos los surcos de una misma profundidad seleccionados vamos a Imagen /Ajustes/ Brillo-Contraste en el menú principal, y le damos a ambos unos valores de 100 para que deje blanco el interior del surco. Esto lo hacemos para eliminar el color de fondo y para 


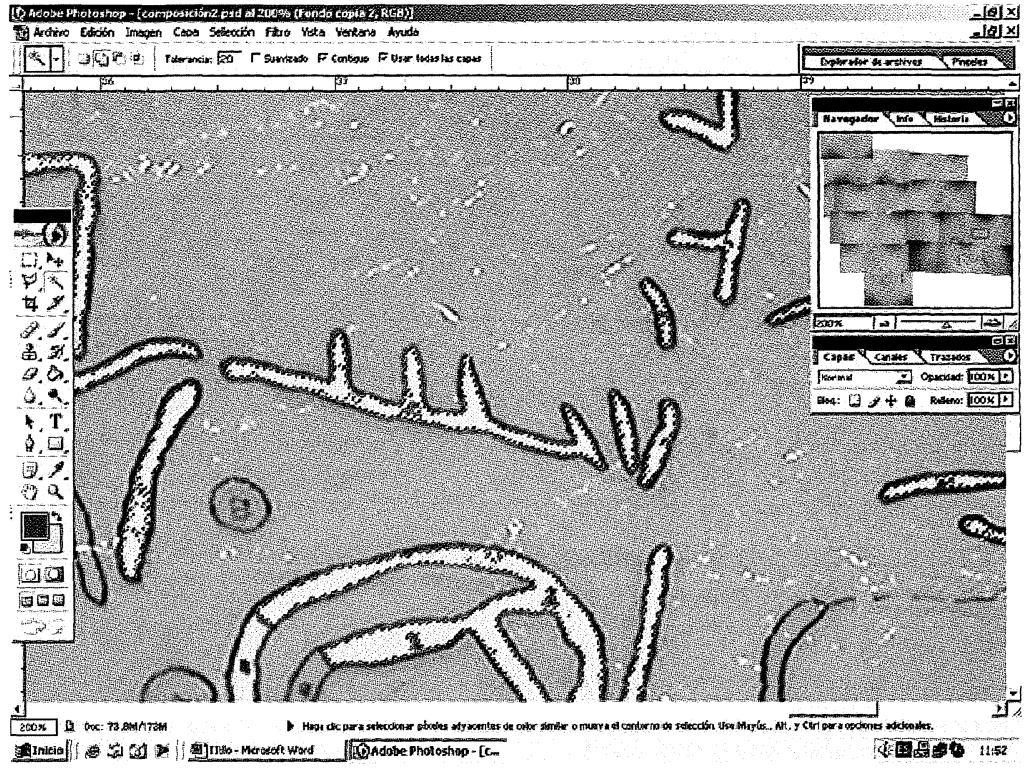

Figura 9.- Selección de los surcos con varita mágica.

que el paso posterior dé unos resultados iguales para todos los surcos de una misma profundidad. Luego, volvemos a repetir la operación y le vamos a dar unos valores concretos que nos van a permitir crear una escala de grises para cada profundidad, correspondiendo el más oscuro con el surco más débil. La varita mágica va a dejar deseleccionada la parte de los números que marcan la profundidad con lo que dentro del surco nos va a quedar una pequeña parte de otro color, pero esto lo solucionaremos más tarde. No debemos olvidar seleccionar también la figura de referencia. Cuando tengamos hecha esta operación, vamos a Edición/Copiar y pegamos toda la selección en el nuevo documento. Ya tenemos así una parte de las figuras, en nuestro caso las que tienen el surco con profundidad intermedia, en el calco definitivo (Figura 10).

Lo mismo hacemos para el resto de las figuras con otras profundidades. Cuando las tengamos todas colocadas en el nuevo documento, sólo nos quedará retocarlas. Vamos a ir a herramientas clonar para hacer desparecer los huecos de los números que marcaban la profundidad y para que nos queden una figuras con un tono más homogéneo. (Figura 11). 


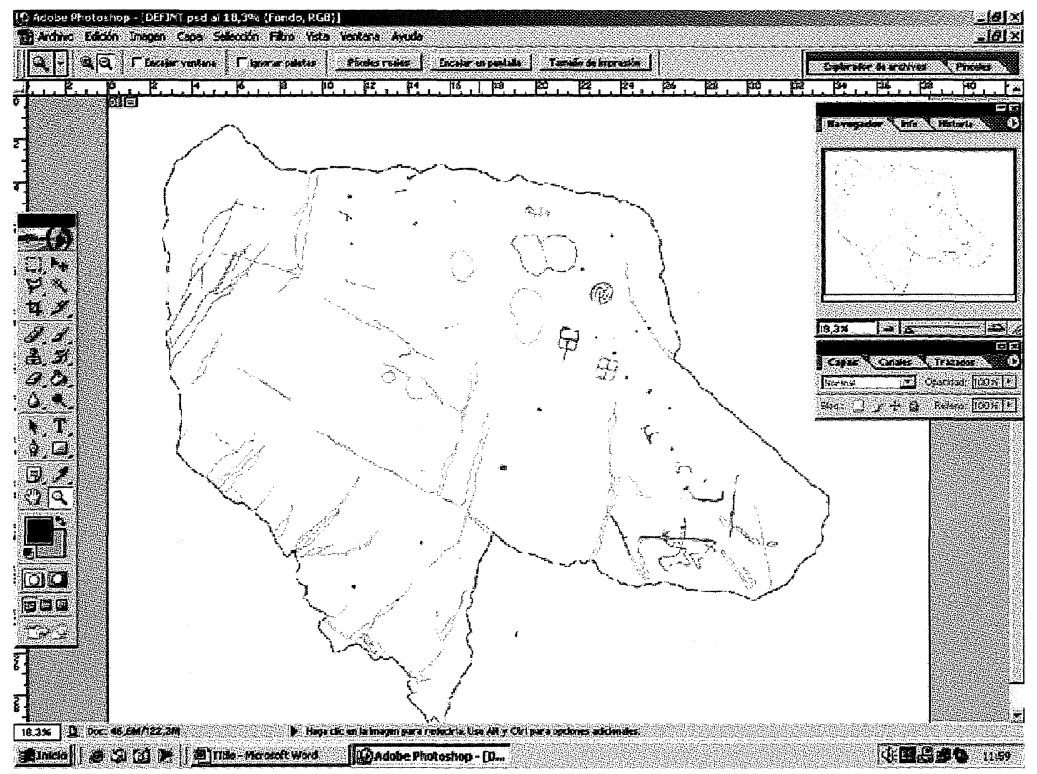

Figura 10.- Inserción de las figuras de profundidad media en el nuevo documento.

Llegado este punto sólo nos queda introducir la escala y el norte en el calco. Para lo primero vamos a crear una escala en otro programa Corel Draw , y la vamos a pegar en el archivo donde tenemos los plásticos originales. En Edición/ Transformar/Escala la ajustamos a la escala real (Figura 12), y luego la copiamos en el calco.

Finalmente sólo queda insertar el norte, para ello vamos a Herramienta Forma personalizada y elegimos en el menú superior la flecha y el color deseados. La insertamos y la rotamos hasta alcanzar el norte geográfico.

Respecto al resultado final, hemos de señalar que depende mucho de las condiciones bajo las que el panel es observado y del rigor con que se hace el levantamiento del calco. Así, sólo realizando un trabajo sistemático y completo tanto en el proceso de observación como el de reproducción, se va a conseguir un calco de calidad, pero sujeto siempre a nuevas adicciones o modificaciones puesto que el resultado final es siempre un producto de autor o autores hecho a partir de juicios individuales o colectivos. 


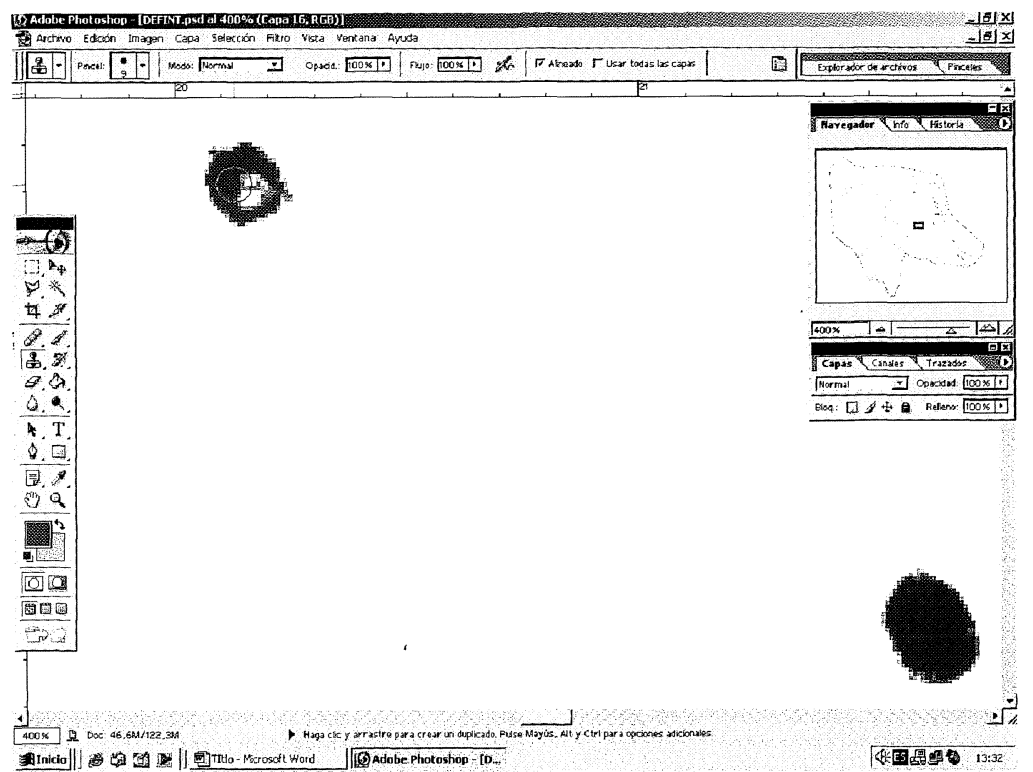

Figura 11.- Clonado de las figuras.

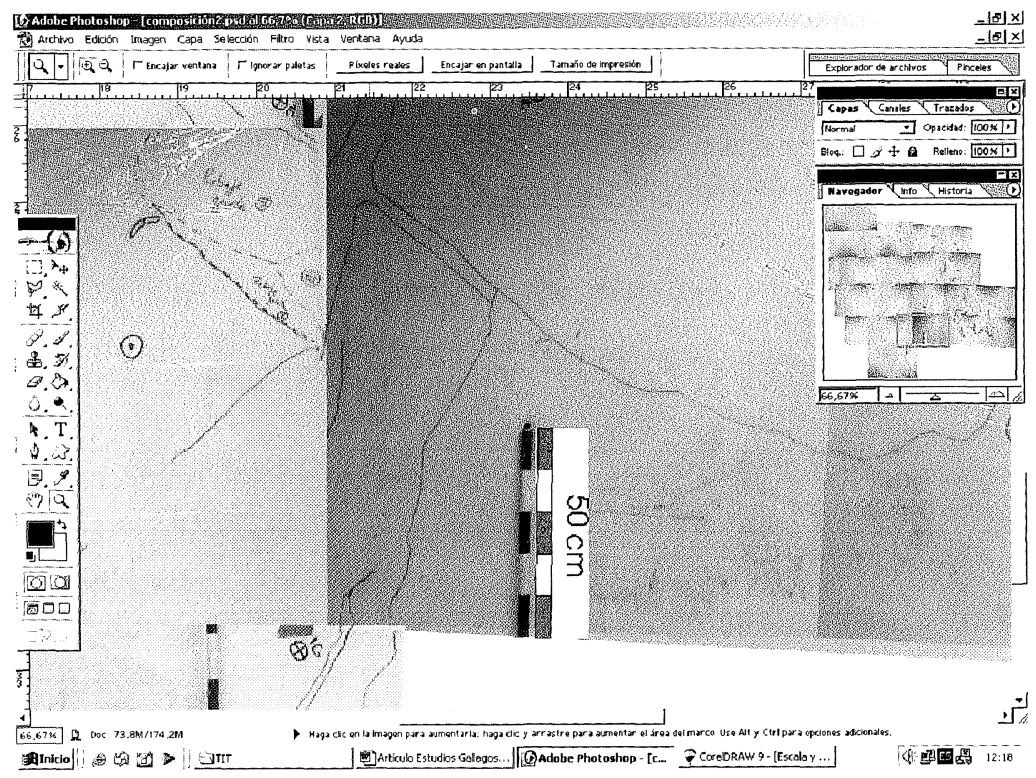

Figura 12.- Ajuste de la escala al original.

Cuadernos de Estudios Gallegos, Tomo LII, Fascículo 118, Santiago 2005. (Págs. 81 - 115) 


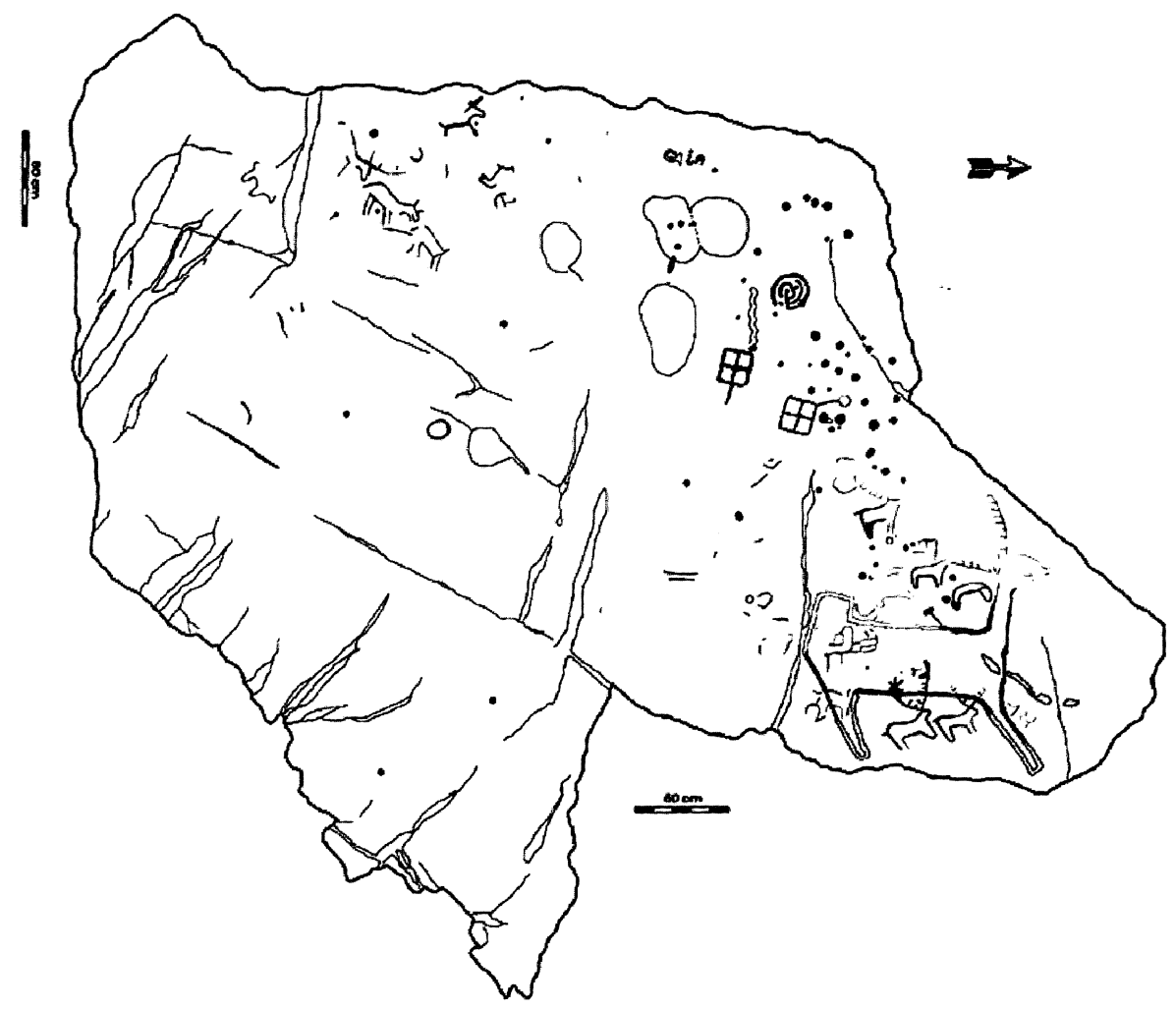

Figura 13.- Calco de Laxe da Forneiriña I, Paredes (Campo Lameiro).

La diferencia de tonalidad en los motivos refleja su distinta profundidad, correspondiendo el más oscuro con el más profundo.

En definitiva, la documentación ha presentado en el pasado un conjunto de limitaciones que han incidido negativamente en su evolución y deslucido las investigaciones de arte rupestre. Sin embargo, se percibe una inminente época de cambio, desde hace menos de una década y gracias a los avances tecnológicos están aflorando numerosos métodos que puede suponer la desaparición de las técnicas tradicionales de reproducción. Este punto de inflexión, que va a dar paso a una nueva página en lo que se refiere a registro de grabados, es un buen momento para reflexionar sobre lo qué es y lo qué ha sido la reproducción en arte rupestre. Pero, sobre todo, es hora de avanzar y explorar, mediante su aplicación y experimentación en campo, todas las potencialidades que estas nuevas técnicas poseen. 


\section{BIBLIOGRAFÍA}

ACUÑA CASTROVIEJO, Fernando; VÁZQUEZ VARELA, José Manuel. «Catalogación de Yacimientos Prerromanos del Ayuntamiento de Santiago». Arqueoloxía/Investigación 3. Santiago, 1987.

BEDNARIK, Robert. La calibración computarizada a color en las fotografias de arte rupestre. [en línea]. 2002. [consulta el 31-01-04]. http://rupestreweb.tripod.com/escala.html.

CACHO TOCA, Roberto; GONZÁLEZ SAINZ, César; FUKAZAMA, Takeo. Arte Paleolitico en la Región Cantábrica: base de datos multimedia Photo VR database, DVD ROM Windows Version. Cantabria, 2003.

CARRERA RAMÍREZ, Fernando. Ficha para la diagnosis del estado de conservación de los petroglifos gallegos. Revista do Museo Municipal Quiñónes de León 9-10, Vigo, 1996, 91-108.

COSTAS GOBERNA, Fernando Javier; ALBO MORÁN, José María; FERREIRA PRIEGUE, Fernando. El petroglifo del Monte Tetón en Tebra (Tomiño) Grupo 1. Petroglifos: Levantamiento de calcos y fotografía. Vigo: Revista do Museo Municipal Quiñones de León 1-2, Vigo, 1988, 27-45.

CRIADO BOADO, Felipe; PARCERO OUBIÑA, César; SANTOS ESTÉVEZ, Manuel. De la arqueología simbólica del paisaje a la arqueología de los paisajes sagrados. Trabajos de Prehistoria. Vol. 54, $\mathrm{n}^{\circ}$ 2. Madrid, 1997.

DOMINGO SANZ, Ignacio; LÓPEZ MONTALVO, E. Metodología: el proceso de obtención de calcos o reproducciones. En La Cova dels Cavalls en el Barranc de la Valltorta. Monografías del Instituo de Arte Rupestre. Museu de la Valltort. Valencia, 2002. 75-81.

GARCÍA ALÉN, Alfredo; PEÑA SANTOS, Antonio. Los grabados rupestres de la provincia de Pontevedra. A Coruña 1981.

MARTÍNEZ CELIS, Diego. Historia de los procesos de documentación de arte rupestre en Colombia. [en línea]. 1997. [consulta el 30/01/2004]. http://rupestreweb.tripod.com/martinez.html.

MATTEINI, Mauro; MOLES, Arcangelo. La química en restauración. tr. por Emiliano Bruno y Giuliana Lain. Sevilla, 2001.

MAYER, Ralph. Materiales y técnicas del arte. tr. por Juan Manuel Ibeas. Madrid, 1988.

MONEVA MONTERO, María Dolores. Primeros sistemas de reproducción de Arte Rupestre en España. Espacio, Tiempo y Forma, serie I, Prehistoria y Arqueología 6, Madrid, 1993, 413-442.

MONTERO RUIZ, Ignacio; RODRÍGUEZ ALCALDE, Ángel; VICENT GARCÍA, Juan M.; CRUZ BERROCAL, M. Técnicas digitales para la elaboración de calcos de arte rupestre. Trabajos de Prehistoria 55 n. 1, Madrid, 1998, 155-69.

PEÑA SANTOS, Antonio De la; REY GARCÍA, José Manuel. Petroglifos de Galicia. A Coruña, 2001.

PICAZO, Jesús; LOSCOS, Rosa; MARTíNEZ, Manuel; PERALES, María Pilar. Las Pinturas Rupestres de la Cueva del Chopo (Obón, Teruel). Kalathos 20-21, Teruel, 2001, 27-83. 
PRIETO, Beatriz. Biodeterioro de rocas graníticas. Contribución de los líquenes al deterioro del Patrimonio Monumental Construido. Santiago, 1997.

REY CASTIÑEIRA, Josefa; SOTO BARREIRO, María Jose. El arte rupestre de Crastoeiro (Mondim de Basto-Portugal) y la problemática de los petroglifos en castros. Braga, 2001.

REY CASTIÑEIRA, Josefa; SOTO BARREIRO, María José. Una metodología de estudio para petroglifos. Resultado en Laxe da Sartaña. Gallaecia 14-15, Santiago de Compostela, 1996, 197-221.

SANSONI, Umberto., GAVALDO, Salvatore., GASTALDI, Cristina. Simboli Sulla Roccia. Campo di Ponte: 2001.

SANSONI, Umberto; GAVALDO, Salvatore. 1995. Il segno e la Storia. Arte rupestre preistorica e medievale in Valchiavenna. Chiavenna, 1995.

SANSONI, Umberto; MARRETTA, Alberto; LENTINI, Salvatore. Il Segno Minore. Arte rupestre e tradizione nella Bassa Valcamonica. Campo di Ponte, 2001.

SANTOS ESTÉVEZ, Manuel. Los espacios del arte: construcción del panel y articulación del paisaje en los petroglifos gallegos. Trabajos de Prehistoria 55, Madrid 1998, 73-88.

SOBRINO BUHÍGAS, Ramón. Corpus Petroglyphorum Gallaecia. Reedición facsimilar del original de 1935, prol de Ramón Sobrino, tr al gallego de Xosé Souto, $2^{\mathrm{a}}$ ed. A Coruña: 2000.

TIMOTHY, Darwill; UCKO, Peter. Rock Art Pilot Project. Main report. London: 2000.

VÁZQUEZ COLLAZO, Santiago; BENAVIDES GARCÍA, Rosa. Traballos de localización e rexistro dos gravados rupestres do ámbito espacial do futuro parque temático da arte rupestre de Paredes (Campo Lameiro-Pontevedra) Memoria técnica-Catálogo depositado en la DXPHD. Inédita. Santiago, 1997.

VICENT GARCÍA, Juan Manuel; MONTERO RUÍZ, Ignacio; RODRÍGUEZ ALCALDE, Ángel; MARTÍNEZ NAVARRETE, María Isabel; CHAPA BRUNET; Teresa. Aplicación de la imagen multiespectral al estudio y conservación del arte rupestre postpaleolítico. Trabajos de Prehistoria 53, n. 2 , Madrid, 1996, 19-35. 